\title{
The Human Eye: Structure and Function
}

\author{
by Clyde W. Oyster \\ Sinauer Associates, \$84.95, 766 pp. \\ ISBN 0-87893-645-9, 1999
}

\author{
ReViewed by Michael F. LAND \\ School of Biological Sciences \\ University of Sussex \\ Brighton, BN19QG \\ United Kingdom
}

The intricacy and seeming perfection of the eye, both as an object of anatomical beauty and as a working machine, have worried and intrigued scientists, philosophers and zealots, especially during the intellectual upheavals of the nineteenth century. For William Paley, such a mechanism argued for a supreme designer; for Darwin, the eye was a test case for natural selection; and for Helmholtz, it was a brilliant compromise - a flawed device to a brass and glass instrument-maker, but a structure nonetheless capable of resolving at the limits that physics allow. In this excellent new book on the eye, Clyde Oyster manages to preserve the sense of awe experienced by our Victorian predecessors, while at the same time providing a solid treatise on eye anatomy and physiology that will certainly serve as a text for those concerned with the function of the eye in health and disease.

As Oyster points out, the eye has several histories: “... an evolutionary history dealing with the emergence of our species and eyes over geological time, a developmental history that unfolds over an individual's lifetime, and an intellectual history extending back at least to the classical age of Greece, that documents human efforts to understand the eye." Part of the charm and, for me, the success of this book is the way that Oyster has permeated the solid subject matter with these three histories. The backbone of the book consists of the 16 chapters on eye anatomy and physiology, but these are leavened by a variety of devices to inform us of the eye's evolution, development and intellectual history. The book begins with a 53-page prolog called "A brief history of eyes", which describes the optical systems of at least ten different animals in an evolutionary context. It will be news to most optometry students that the eyes of scallops and shrimps use mirrors rather than lenses, that spiders are almost the only other creatures to use 'our' kind of single chambered cornea-based optical system, or that there are five distinct types of compound eyes. Aside from specialist reviews, this is the best text-book treatment of eye evolution that I know of.

The main text is divided, somewhat arbitrarily, into "Ocular Systems" and "Ocular Components". The "Ocular Systems" section describes the bony orbit, the eye muscles, the nerves, blood supply and lachrymal system, whereas the "Ocular Components" section includes the cornea, anterior chamber, iris, ciliary body, lens, and four chapters on retina. Each chapter is a skilful blend of anatomy and up-to-date physiology. The book does not include color figures, presumably to keep the price within students' budgets, but the illustrations are, with a few exceptions, clear and well-designed.

The development of the eye is discussed in various ways. Chapter 1 , "The formation of the human eye," focuses on overall eye embryology, whereas most of the other chapters have sections that explain the ontogeny of the individual parts of the eye. The book ends with an epilogue called "Time and change," which does not present a comforting account for those of us over 50 of the way accommodation, resolution and other functions change over a lifetime. Chapters also contain short, interesting, 'boxed' articles summarizing key discoveries in eye research that are related to the rest of the material in each chapter. These vignettes describe key figures and events in the elucidation of visual function - the box in Chapter 1 highlights the embryological studies of Ida Mann, whereas the chapter on ocular geometry includes an account of the first demonstration of the eye's inverted image by Kepler and Scheiner. The nerves of eye and orbit are enlivened by Sherrington, and the chapter describing retinal function recapitulates the pioneering studies of Schultze, Golgi and Cajal. Even eye research specialists will learn something new from these summaries - I had no idea that the eye muscles were first properly described by Fallopius (of tube fame) and Eustacius (of different tube fame), or that the Zonule of Zinn (suspensory ligament of the lens) was described by an exbotanical illustrator who also gave his name to the flower, the Zinnia.

The chapter on the extraocular muscles is an excellent example of the unique approach that the entire book takes. It begins with an explanation of eye movements and why we have them, moves on to a discussion of the causes and consequences of strabismus, then describes the neural control and molecular mechanisms of muscular force production. The chapter goes on to explain ocular muscle and nerve physiology, anatomy and development, and also includes historical and methodological vignettes covering the original detection of ocular misalignment, and strabismus surgery. The other chapters follow a similar multidisciplinary pattern. I found this to be a comprehensive, authoritative and entertaining book. As Oyster writes in the preface: "My sense of storytelling has prompted a leisurely pace with diversions, digressions, and some dawdling to admire the view." A potential problem for students with a 'mission' may be that there is too much diversion here-not all of this book is needed to pass examinations! In a vignette on the nineteenth century polymath Helmholtz, Oyster mentions that a student complained to the education ministry alleging that Helmholtz' lectures on anatomy were "inadequate" because he insisted on discussing physiology as well. Thus, not everyone will want the rounded education that this excellent book provides.

\section{Cardiology: the Evolution of the Science and the Art}

\author{
by Richard Bing, editor \\ Rutgers University Press, \$55, 368 pp. \\ ISBN: 081-35262-72, 1999 \\ Reviewed by Galen S. WAgner \\ Associate Professor, Division of Cardiology \\ 2400 Pratt St \\ Box 3636 Medical Center \\ Durham, North Carolina 27710, USA \\ Email:wagne004@mc.duke.edu
}

It was a pleasure to read the second edition of Richard Bing's book Cardiology: the Evolution of the Science and the Art. I did not read the first edition, so all of the contents were new to me. There were several essential elements that made this experience enjoyable for me.

Although many authors contributed 